\title{
HIGH ENERGY HALOGEN ATOM REACTIONS ACTIVATED BY NUCLEAR TRANSFORMATIONS
}

\author{
Progress Report for Period
}

February 15, 1979, to February 14, 1980

Edward P. Rack, Project Director

DEPARTMENT OF CHENISTRY

THE UNIVERSITY OF NEBRASKA-LINCOLN

IINCOLN, NEBRASKA 68583

\section{MASTER}

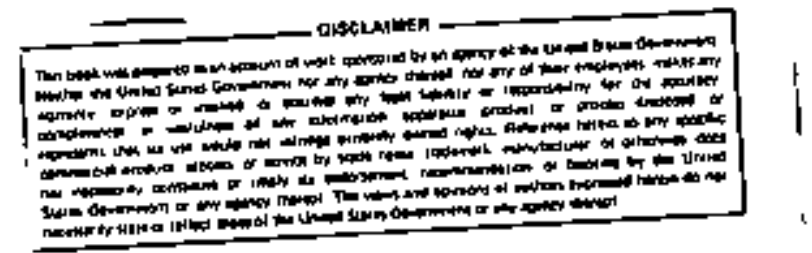

PREPARED FOR U. S. DEPARTMENT OF ENERGY

UNDER CONTRACT NO. EY-76-S-02-1617.A002

FEBRUARY， 1980 


\section{DISCLAIMER}

This report was prepared as an account of work sponsored by an agency of the United States Government. Neither the United States Government nor any agency Thereot, nor any of their employees, makes any warranty, express or implied, or assumes any legal liability or responsibility for the accuracy, completeness, or usefulness of any information, apparatus, product, or process disclosed, or represents that its use would not infringe privately owned rights. Reference herein to any specific commercial product, process, or service by trade name, trademark, manufacturer, or otherwise does not necessarily constitute or imply its endorsement, recommendation, or favoring by the United States Government or any agency thereof. The views and opinions of authors expressed herein do not necessarlly state or reflect those of the United States Government or any agency thereof. 


\section{DISCLAIMER}

Portions of this document may be illegible in electronic image products. Images are produced from the best available original document. 


\section{NOTICE}

This report was prepared as an account of work sponsored by the United States Government. Neither the Uníted States nor the United States Department of Energy, nor any of their employees, nor any of their contractors, subcontractors, or their employees, makes any warranty, express or implied, or assumes any legal liability or responsibility for the accuracy, completeness, or usefulness of any information, apparatus, product or process disclosed or represents that its use would not infringe privately owned rights. 


\section{PROJECT ABSTRACT}

High energy reactions of halogen atoms or ions, activated by nuclear transformations, have been studied in gaseous, high pressure and condensed phase saturated and unsaturated hydrocarbons, halomethanes and other organic systems in order to better understand the mechanisms and dynamics of high energy monovalent species. The experimental and theoretical program consists of six interrelated areas: (1) The reactions of jodine with alkenes and alkynes activated by radiative neutron capture and isomeric transition in low pressure gaseous systems employing additives and rare gas moderators, high pressure and liquid systems. Special attention was given to the reactivity of excited complex formation and structural effects of electrophilic lodine attack on various pi-bond systems. (2) The gas to condensed phase transition in halogen high energy chemistry. Current interest involves the study of caging effects of an ice lattice on recombination reactions involving neutron-irradiated frozen aqueous solutions of halogenated organic and biochemical solutes in order to learn more about kinetic energy effects, halogen size, solute molecule size, steric effects and hydrogen bonding within an ice lattice cage. Systematics of halogen hot atom reactions. The reactions of

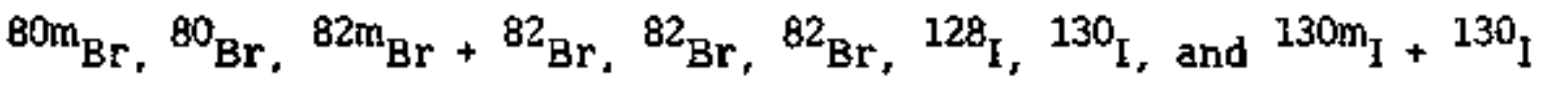
activated by radiative neutron capture or isomeric transition in hydrocarbons and halo-substituted alkanes in low pressure and high pressure gaseous systems employing additives and rare gas moderators are currently being studied. (4) Mathematical and computer simulation studies of caging events within an ice lattice are being investigated. 
(5) At Brookhaven National Laboratory, cyclotron-produced chlorine and fluorine hot atoms substitution reactions with molecules possessing a single chiral center are under investigation. Experiments are being performed in an attempt to determine the role of hot atom kinetic energy, halogen atom, enantioner structure, steric effects and phase on the extent of substitution by retention of configuration or by Walden inversion. (6) The applications of high energy techniques and concepts to neutron activation analysis for trace elements and trace molecule determinations in biological systems was continued.

4 


\section{FACILITIES}

\section{A. Triga Mark_I Reactor}

All neutron irradiations were made in the Triga Mark I "swimming pool" nuclear reactor at the Veteran's Administration Medical Center in Omaha, Nebraska. A flux of $1 \times 10^{11}$ thermal neutrons $\mathrm{cm}^{-2} \mathrm{sec}^{-1}$ was present at an operating power of 15.5 kilowatts. Various positions in the "lazy susan" sample holder were employed and the assembly was rotated to ensure that all samples received the same neutron flux and radiation dose. For very short irradiations, the assembly was not rotated and samples were irradiated in the same position. The radiation dose was approximately $3 \times 10^{17}$ e.v.g. ${ }^{-1}$ min $^{-1}$ using Fricke dosimetry.

For the past year, the nuclear reactor operated routinely for at least four eight-hour days a week at 15.5 kilowatts. The radiochemistry group used for the period from October 1, 1978, to September 30, 1979, 410 hours (integrated time in reactor) at 15.5 kilowatts power, making 2100 irradiations.

\section{B. Radiochemistry Laboratory}

All sample preparations were performed in a well-equipped, specially-designed radiochemistry laboratory in Hamilton Hall Chemistry building. The two hot laboratories contain four six-foot "Oak Ridge-Typen hoods, several radioactive waste sinks, radiation safety equipment, seven separate vacuum lines for preparing gas, high pressure gas, liquid and solid state systems, and the usual Jaboratory facilities. The counting roon is equipped with one radiogas chromatograph, three single-channel analyzers with several $2^{2} x 2^{\prime \prime} \mathrm{NaI}$ crystals, four GM counting stations, four gas-flow counters, and a Nuclear-Data 128-channel analyzer with a $3^{\prime \prime} \times 3^{\prime \prime}$ NaI crystal specially housed in a concrete, cadium, and lead cave. 
Two complete radiogas chronatographs have been built and are located in the radiochemistry room of the reactor facility. allowing us to analyze routinely many more samples containing ${ }^{128} \mathrm{I},{ }^{80} \mathrm{Br}$, and ${ }^{38} \mathrm{Cl}$. This is quite necessary for the study of ${ }^{128}$ I reactions activated by the $(n, \gamma)$ process in the acetylenes and the various isomers of butene and pentene in both the gas and condensed states, precluding the necessity of making severe corrections for radiation damage and thermal reactions occurring during lengthy neutron irradiations. An ISCO Model 1440 High Performance Liquid Chromatograph with sample collector is located at the reactor facility. This location enables us to study efficiently the caging effects of an ice lattice on high energy reactions with organic molecules and biomolecules. We have increased our data-gathering ability by having our equipment located at the reactor site. 


\section{SUMMARY OF PRESENT PROGRAM}

\section{A. Background of Project}

Hot atom, high energy or "hot" chemistry, is an important tool for basic reasearch in areas now considered vital-energy, environment and medical or related technology. "Hot" chemistry is a probe, an interactive science which embraces many fields; from hot atom reactions in simple hydrocarbon systems to theoretical development of high energy particle reactions. Utilizing reactive species possessing non-Boltzmann energy distributions, high energy chemists have discovered and characterized new reaction channels in organic and inorganic systems; contributed to the theories of energetics, dynamics and systematics; developed new techniques of chenical detection and analysis; and aided biological and medical sciences.

High energy distributions of atoms and/or ions can be produced via two classes of activation: chemical accelerators and bulb techniques. Each type of experiment produces reactions that can contribute to the characterization of high energy species. Each experimental class investigates properties unique to its technique.

Chemical accelerators impart kinetic energy to atoms, ions or molecules by use of electronagnetic, pressure differential or witrasonic gradients. The particles are accelerated in a straight line (linear or tangential, hence the name. "beam" experiment) with a resultant kinetic energy distribution of narrow bandwidth (generally a Boltzmann distribution centered about the terminal accelerator energy). The atomic-. ionic- or molecular-beam is produced in a near vacuum and permits the examination of atom-molecule and/or ion-molecule single collision reactions. The data obtained reveal information on intrinsic properties 
of reactions; e.g., reactive cross sections as functions of scattering angle and energy. However, chemical accelerators are limited in their abilities to measure endoergic reactions, to have (energy) resolution and (product) Identification simultaneously, to orient molecules (dynamics), and to study the effect of environment (even 1 torr pressure) and multiple collisions on reactivity.

Bulb techniques are multi-collisionally oriented. The kinetic energy imparted to atoms or ions are the result of nuclear recoil or photochemical recoil activation. While photochemical and some nuclear activation modes produce atoms, lons or radicals within narrow kinetic energy limits, the multi-collisional nature of the technique results in collisional "cooling" of the "hot" entities, producing a broad spectrum of kinetic energies.

Extrinsic properties are readily measured (the hot species or mediun taken in bulk) and intrinsic properties are inferred. New reaction channels (both exo- and endoergic) have been observed and characterized. Although molecules cannot be orjented, the ease of product identification (including diastereomers and enantiomers) permits study of reaction dynamics. The effect of the molecular environment on the reaction systems from low pressure gas to solid state glasses and crystals is easity studied in bulb experiments. These studies can significantly contribute to a better understanding of the photocatalytic cage effects or de-excitation processes, an area that may be important in photochemical energy conversion processes.

In our research work; we are interested in the area of monovalent high-energy physical-organic chemistry, concentrating on heavy halogens activated by radiative neutron capture and isomeric transition 
and cyclotron produced fluorine and chlorine. We have also used photochemistry, ion cyclotron resonance and mass spectrometry techniques in our work.

During the period February 1979 to January 1980, five publications appeared in the literature, two are currently in press and one has been submitted for publication. The lead talk. "Lịquid Phase Hot Atom Chemistry: At Crossroads" which I presented at the 10th International Hot Atom Chemistry Symposium in Loughborough, U.K. will appear in a special issue devoted to the lead lectures of the Symposium in Radiochimica Acta. The reader may acquire a flavor of the current work that is being done by the group in the last several years. As much of our progress of the past contract year is contained in publications and manuscripts.in-press or submitted, only a brief discussion relating the relevance, progress and slgnificance of the work will be presented.

B. Summarized below is a report of our main progress during the current contract period.

1. Reactions and Systematics of Iodine Reactions with Alkenes and Alkynes.

Relevance. Olefins, acetylene and acetylenic molecules are unsaturated hydrocarbons which, unlike saturated hydrocarbons and halomethanes, are characterized by an electron-rich pi-bond system. High energy (hot) atoms or jons can undergo substitution and abstraction reactions with saturated hydrocarbons and halocarbons. Similar reactions can occur in hot atom-olefin (or acetylene) systems: Furthermore, unsaturated systems can undergo additional reactions to the pi-bond system by electrophilic attack initiated by high energy, elec- 
tronically excited, or thermal fodine ions resulting in stable organic products.

Activation of iodine species by radiative neutron capture, isomeric transition and other nuclear transformations (and photochemical irradiation) can provide translationally and electronically excited as well as charged species which in reaction can provide direct information for the development of a kinetic theory of "hot" electrophilic attack and indirect dynamics evidence as functions of multiple bond location and steric (spatial) effects.

In a previous publication, ${ }^{1}$ we presented evidence for an excited reaction intermediate in the $(n, \gamma)$-activated reactions of iodine with acetylene. In order to determine the effects of structure on the formation of the electronically excited reaction intermediate, we stuoied, employing the density-variation technique, ${ }^{2}$ rare gas additives, oxygen, etc., the reactions of high energy iodine with propyne, ${ }^{2} 1$-butyne and 2-butyne. ${ }^{3}$ In addition, our goals in this project are similar to those of our olefin work, to evaluate all our existing data and to attempt to develop rules for high energy ion electrophilic attack on the triple bond systems, and to determine the importance of steric and bond location effects.

As this work has now been published in two full papers 2,3 in the Journal of Physical Chemistry only its progress and significance will be mentioned.

(a). Preferential Site Attack with Formation of an Excited Reaction Intermediate by High-Energy Iodine with Propyne ${ }^{2}$.

Progress. The reactions of $128_{1}$ activated by radiative neutron capture with propyne occur primarily through an addition channel 
forming an electronically excited reaction. intermediate. Propyne is similar to acetylene, but unlike olefins, in that no photochemical addition occurs under conditions simulating. sample handiing. In an excess of gaseous propyne at 700 torr pressure $22.9 \pm 1.6 \%$ of ${ }^{128} \mathrm{I}$ is stabilized as organic activity to the following extent: $\mathrm{CH}_{3} 1.3 .238$; $\mathrm{C}_{2} \mathrm{H}_{5} \mathrm{I}, 2.048 ; \mathrm{CH}_{3} \mathrm{CHICH}_{3}, 10.0 \%$; and $\mathrm{C}_{2} \mathrm{H}_{5} \mathrm{CHICH}_{3}, 7.61 \%$. Rare gas additive studies suggest that the iodine reaction with propyne occurs mainly by virtue of its kinetic energy. In addition, oxygen additive and gas to condensed phase transition experiments suggest that the iodine-propyne complex is highly excited, undergoing decomposition, addition to propyne, and stabilization and hydrogen abstraction reactions. The major stabilization product is $\mathrm{CH}_{3} \mathrm{CHICH}_{3}$ suggesting preferential electrophilic iodine site attack on the central carbon of propyne.

\section{Significance}

1. The kinetic energy of the electrophilic jodine is quite important in the reaction with propyne. On the other hand, except for a hot contribution to the ethyl lodide product, the jodine-acetylene complex can be formed by thermal iodine electrophilic attack.

2. The iodine-propyne complex contains more internal excitation energy as evidenced by the effect of the gas to condensed. phase transition on the complex decomposition praducts $\mathrm{CH}_{3} \mathrm{I}$ and $\mathrm{C}_{2} \mathrm{H}_{5} \mathrm{I}$. and complex addition to propyne. We suggest that the $\mathrm{CH}_{3} \mathrm{CHICH}_{3}$ enhancement yield increase is due to the caging of the electronically excited complex.

3. Stanilar to the lodine-acetylene system, ${ }^{15}$ we believe that kinetic energy, positive charge, and preferential electrophilic attack on the propyne pi-bond system results in a highly excited complex with 
unimolecular (low pressure) and caged complex and cage radical (high pressure and liquid) characteristics. In a future study employing cyclotron bombardment, it will be interesting in studying the reactions of neutral ${ }^{126} \mathrm{I}$ reactions with alkynes, observing whether a reaction complex is formed.

(b). Product Formation Routes and Chemical Selectivity of High Energy Iodine Reactions with Butyne Isomers $^{3}$

Progress. Reactions of recoil produced lodine-izs with isomers of butyne were studied in gaseous, high pressure, and condensed phase conditions, with rare gas additives and in the presence and absence of radical scavengers $\left(\mathrm{I}_{2}\right.$ and $\left.\mathrm{O}_{2}\right)$. It was found that recoil iodine-128 reactions were initiated by thermal electronically excited $\mathrm{I}^{+}$species for both 1-butyme and 2-butyne systems. While the diverse and complex nature of the reactions cannot be explained by simple chemical parameters, comparisons among the alkyne systems demonstrate preferential attack of fodine at the triple bond resulting, mainly, in electronically excited intermediates. A comparison of the various product formation routes results in the characterization of general traits common to the alkynes.

Significance, From our previous studies of recoil todine-128 reactions with olefin systems, ${ }^{4-9}$. we have found these reactions to be diverse and complex. A cursory examination of these iodine pi-bond systems showed no systematic trend with simple chemical or physical parameters. However several important generalizations ${ }^{9}$ were made. Thermal ${ }^{128} \mathrm{II}^{+}$reactions play an important role in the various product formation routes of all the alkenes studied except 1-butene. Labeled ${ }^{\prime} \mathrm{CH}_{3} \mathrm{I}$ was a major product in all systems studied, the magnitude of the 
yield increasing with the number of carbons on the alkene. Unlike other recoil atoms such as tritium, fluorine, and clilorine, recoil iodine128 displays preferential attack at or near the pi-bond. However the various organic products were formed by diverse reaction channels. By comparison with our previous studies of acetylene ${ }^{l}$ and propyne. ${ }^{2}$ the following trends or observations become apparent for recoil iodine-128 reactions with alkyne systems, (1) Recoil iodine-128 displays preferential attack at or near the triple bond of all the alkynes studied. Reaction'primarily through an addition channel forming an electronically excited reaction intermediate dominates all the alkynes studied. This intermediate can undergo further reaction such as decomposition, stabilization, and abstraction, and further addition reactions with bath alkyne molecules. ${ }^{128}$ I reactions with acetylene occur exciusively by the initial formation of an istermediate. Iodine-128 reactions with propyne and 2-butyne also occur exclusively by the initial formation of the intermediate in gaseous systems. However, in 1-butyne which has two carbons removed from the pi-bond, we have the first evidence in the alkynes of substitution away from the triple bond. We suggested the formation of $\mathrm{CH}_{3} \mathrm{I}$ as occurring by a substitution reaction for the $\mathrm{CH} \mathrm{CCH}_{2}{ }^{\circ}$. Unlike the olefins, we found evidence for cageradical contributions in liquid propyne and butyne isomers. (2) Except for the progyne systems where iodine kinetic energy is a requirement for reaction, reactive species are thermal excited $\mathbf{I}^{+}$; unlike the olefins there is no evidence for any reaction channels involving ${ }^{128} \mathrm{II}^{+}$. The major stabilization products of all reaction systems studied are saturated fodoalkanes. Where unsaturated iodides result their yields decrease with increasing system density. Considering excited reactive 
intermediates, it is reasonable to assume that the thermodynamically more stable product will be formed if energy- barriers, molecular rearrangements, and other kinetic parameters do not forbid abstraction reactions. Secondly, if caging reactions occur a reactive cage wall of the alkyne supplies the necessary hydrogen needed for saturation. As mentioned previously, hydrogen abstraction is an endoergic process providing an energy sink for excited radicals-alfowing a decrease in internal energy. (4) Methyl iodide is a major product in all the alkyne systems studied. As we have observed in the olefin systems, the $\mathrm{CH}_{3} \mathrm{I}$ yield increases with increasing number of carbons. For the oneatmosphere acetylene, propyne, 1-butyne, and 2-butyne, the $\mathrm{CH}_{3} \mathrm{I}$ yields are $0.49 \%, 3.23 \%, 4.49 \%$, and $6.9 \%$, respectively. (5) There is a definite structural effect in iodine reactions with alkynes as shown previously and in this study. For example, the product formation routes involving an intermediate for the alkynes suggests the importance of steric factors and energy deposited into the intermedate in determining the nature of the products.

In summary, the preferential electrophilic attack by iodine on the pi-bond allows the use of recoil atom bulk techniques as a probe of new reaction channels not readily observed by other techntques.

2. Gas to Liquid to Solid Transition in High Energy Chemistry.

Relevance. While the gas phase studies of any system may lead to discovery of new high-energy reaction channels, the gas phase quite often does not resemble the final, technological end product to which the system can be applied. The liquid or solid phase system is often ideally suited for chemical, technological or environmental application 
on an industrial scale. The dilemma lies in the often too complex nature of condensed phase systems. Dynamic, systematic and energetic information is more difficult to extract from high density data than the low pressure gas counterparts. The gas to liquid to solid transition provides a continuity between simple research (gas phase) systems and their applicable end-product (often the condensed phase).

By systematic use of the gas to condensed phase transition, the effects of a collapsing molecular environment on high energy atoms or ions and their reaction channels can be observed. The resulting data contribute information as to the nature and importance of various reaction channels; the emergence of new reaction products (channels), not found in the gas phase; and the relative importance of molecular versus enhancement reactions in the condensed phase.

The nature of condensed phase enhancement reactions has been a controversial subject since the beginning of hot atom chemistry. The interplay of the gas to liquid to solid transition experiments with theoretical chemistry provides a reatistic link between observation and postulation. The characterization of phase transitions of any system provides feedback for refinement of enhancement yield theories (see Section 4). However, we realize that care must be employed not to overinterpret gas to condensed phase data. We do not employ the density-variation technique as a kinetics tool to extract quantitative information but a mechanistic probe to develop reaction schemes as seen in the previous section and to observe the effects of a collapsing molecular enviromment on high energy reaction products.

In the same manner, the gas to condensed phase transition studies on diastereomers and enantiomers provide information for the refinement 
of current concepts of molecular dynamics of hot atom or ion reactions with organic substrates (see Section 5 ).

Progress.

(a) Caging Effects of an Ice Lattice on High Energy Halogen

Recombination Reactions with Monoidotyrosine and Diiodotyrosine ${ }^{11}$

Progress. In an important preliminary study, Willard et. al. 10 found unusually high organic yields of $(n, \delta$ - activated high energy bodine-128 in dilute aqueous solutions of $\mathrm{CH}_{3} \mathrm{I}$. Because of the lack of suitable analytical procedures, no conclusions could be made as to the mechanism of the process. In a preliminary study we reinvestigated the problem by employing dilute liquid and frozen aqueous solutions of monoiodotyrosine (MIT) and diiodotyrosine (DIT). Biomolecules are quite ideal for this type of study because of their solubility in water and the ease of their detection by high performance liquid chromatography (LC). The important result in this preliminary study was that the only observable labelled products for both the frozen and liquid systems were the ${ }^{228}$ I-labeled iodide ion and original substrate molecules FIT or DIT. Unlike the liquid systen where the ${ }^{128}$ I-labeled MIT or DiT product yield decreased to zero with decreasing-concentration, the results of the frozen MIT and DIT solutions were quite different. The recombination absolute yields of ${ }^{128}$ I as MIT and DIT remained constant over the $100-$ fold concentration range. In addition, for the MIT system, the $128_{1}-$ yield appears constant at about $75 \%$ and in the DIT system increases gradually to $58.2 \%$ at the most dilute condition. The iodide-128 yield does not appear to extrapolate to 100 as in the liquid state. We can understand these results by realizing the structure of ice where $\mathbf{H}_{2} \mathrm{O}$ molecules are arrayed in a hexagonal pattern by 
hydrogen bonding with a large amount of empty space between the molecules. We suggest the individual MIT or DIT molecules are trapped in these empty spaces and are exposed to a cage effect not encountered in organic systems. The relative constancy of the absolute values of the ${ }^{128_{I}}$ leading to geminate recombination does not vary greatly within experimental error over the concentration range. This strongly suggests that the ${ }^{128}$ I remains quite close to its organic radical by virtue of the efficient caging abillty of the ice lattice.

Significance. These results suggest that caging effects of high energy reactions with various organic molecules can be studied in ice mixtures.

(b) Radingrotection of Halogenated Biomolecules by an Ice Lattice

progress. Present in the nuclear reactor is a high heterogeneous radiation flux to which all neutron-irradjated samples are subjected. We observed visually during the Irradiation of samples of some of the aqueous systems of biomolecules such as MIT or DIT that $\mathrm{I}_{2}$ was formed in the liquid samples but not in the solid systems. It was of importance to us to Investigate the radiation effects of liquid and solid systems further.

Audtoradiation-induced decomposition of aqueous solutions of radiopharmaceuticals is a widespread problem, especially in long term storage. In order to understand the radiation effects better in the frozen systems, we chose to study dilute aqueous solutions of the halouricils wose radiation chemistry in the liquid state has already been extensively studied ${ }^{12-15}$, and because of their widespread application in and of their importance for biological systems. Polythylene vials containing $5 \mathrm{~mL}$ volumes of dilute aerated aqueous mixtures of 
5-bromouracil (5 BrUra) and 5-jodouracil (5 IUra) in the liquid $\left(25^{\circ} \mathrm{C}\right.$ ) and frozen states $\left(-77^{\circ} \mathrm{C}\right)$ were irradiated for times ranging from 1 to 45 minutes in the Omaha, Nebraska V. A. Medical Center Triga reactor. Absorbed doses were generally in the range $3 \times 10^{17}-1.4 \mathrm{X}$ $10^{19} \mathrm{eVg}^{-1}$. Samples were analyzed immediately by LC and the $1 \mathrm{~mL}$ eluents counted in a $2^{\prime \prime} \mathrm{NaI}(\mathrm{T})$ well detector in a manner described in the Experimental Section.

We determined consumption curves, expressed as percent survival of 5-iodouracil and 5-bromouracil as a function of radiation dose, respectively, at two different concentrations for aqueous and frozen systerns. No attempt was made in these experiments to remove the $H$ atoms and $\mathrm{OH}$ radicals produced by the radiolysis of water or to prevent secondary reactions ${ }^{16}$ in order to insure that the halouracils are consumed by the reactions of the hydrated electrons. Under our experimental conditions only a few electrons are trapped in crystalline ice $^{17}$. Rather we studied, at this time, neat solutions in the lyquid and frozen states which would more resemble aqueous solutions of radiopharmaceuticals or aqueous solutions of biomolecules subjected to a radiation flux. We observed, for the liquid systems, an exponentlal decrease in 5-iodouracil and 5-bromouracil concentrations, similar to that observed for the radiolysis of aqueous solutions of p-bromophenol ${ }^{16}$. The more dilute aqueous system is more sensitive to radiation. We would expect a decrease in sensitivity to radiation for the frozen systems because of the lack of mobility of the "frozen" species produced by the radiation. However, we would expect upon thawing a. liberation of the long-lived radicals or reactive species and these would have a destructive effect on the halouracil. There is no 
apparent decrease in halouracil concentrations for the frozen systems over a large radiation dose range. The G(-XUra) values for the frozen systems appear independent of initial halouracil concentrations and are zero within experimental error. Apparently caging of the halouracil by the ice lattice results in a radioprotection to biomolecules not observed in liquid systems.

In order to test the generality of the above mentioned effect, we measured the survival of the various halogenated biomolecules in the aqueous frozen state irradiated in the nuclear reactor. As show in Table I after a radiation dose of $9 \times 10^{18} \mathrm{eVg}^{-1}$, the survival is or near $100 \%$.

Significance. These results suggest that freezing of aqueous solutions of radiopharmaceuticals can prevent alutoradiation-induced decomposition over extended periods of storage and that biomolecules labeled employing the Szilard-Chalmers labeling technique in an ice lattice can be protected from radiation. However, until this procedure is tried enploying cyclotron irradiation condstions, it will not be known how generally applicable this technique is to other than neutron irradiation conditions. This phase of our work is completed and its manuscripts has been submitted for publication. 
TABLE I

Survival of halogenated biomolecules in the aqueous frozen state irradiated in nuclear reactor

\begin{tabular}{|c|c|c|c|c|}
\hline . & $\begin{array}{l}\text { Inftisl } \\
\text { Concentration } \\
\text { mg/al }\end{array}$ & $\begin{array}{l}\text { Radiation } \\
\text { Dose } \\
\text { eVg }\end{array}$ & $\begin{array}{c}\text { t } \\
\text { Survival }\end{array}$ & \\
\hline 2-Chloroaniline & 0.3 & $9 \times 10^{18}$ & 97.3 & \\
\hline 3-Chloroaniline & 0.3 & $9 \times 10^{18}$ & 98.3 & \\
\hline 4-Chloroaniline & 0.3 & $9 \times 10^{18}$ & 95.0 & \\
\hline 5-Chlorouricil & 0.3 & $9 \times 10^{18}$ & 98.0 & \\
\hline $\mathrm{DL}-\mathrm{p}$-Chlorophenylalanine & 0.8 & $9 \times 10^{18}$ & 100.0 & $\cdot$ \\
\hline 2-Bromaaniline & 0.15 & $9 \times 10^{18}$ & 90.3 & \\
\hline 3-Bromoaniline & 0.14 & $9 \times 10^{18}$ & 95.0 & \\
\hline 4-Bromoaniline & 0.15 & $9 \times 10^{18}$ & 91.7 & . \\
\hline 5-Brontouricil & 0.02 & $9 \times 10^{18}$ & 100.0 & \\
\hline 5-Bromo-2' -Deoxyuridine & 1.0 & $9 \times 10^{18}$ & 98.9 & \\
\hline 2-Iodosniline & 3.0 & $9 \times 10^{18}$ & 96.6 & \\
\hline 3-Iodoaniline & 1.7 & $9 \times 10^{18}$ & \pm 02.0 & \\
\hline 4-Iodoaniline & 0.2 & $9 \times 10^{18}$ & 103.6 & . \\
\hline S-Iodouricil & 0.02 & $9 \times 10^{18}$ & 100.0 & \\
\hline 3-Iodo-L-Tyrosine & 0.3 & $9 \times 10^{18}$ & 96.6 & \\
\hline 5-Iodo-2' -Deoxyuridíne & 1.0 & $9 \times 10^{18}$ & 101.0 & \\
\hline 5-Iodo-5'-Deoxyadenosine & 0.9 & $9 \times 10^{18}$ & 101.0 & \\
\hline 3,5-Diiodo-L-Tyrosine. & 0.2 & $9 \times 10^{18}$ & 99.3 & \\
\hline
\end{tabular}

+Represents the percent of the initial amount of biomolecule irradiated in the frozen aqueous state surviving after absorbing the indicated radiation dose. It is determined by integration of the "UV" peak of the biomolecule botained with an ISCO HPLC utilizing a Partisil - 10 ODS-2 column. 
(c) Caging Effects of an Ice Lattice on High Energy. Halogen Recombination Reactions with Various Halogenated Biomolecules and Organic Molecules

Progress. There are various reasons for measuring product distributions for various halogenated organic moleucles and biomolecules in frozen aqueous solutions at varying solute concentrations. It is important to determine if the constant yield results over a large concentration range in frozen solutions are general for halogenated organic molecules or biomolecules. If so, are the only two products the labeled biomolecule or organic molecule and the labeled halide ion. it is important to determine if the hot atom recombination with its radical is by geminate recombination without any rearrangement in the radical. By measuring the various product yields of the halogenated molecule for selected compounds it may be possible to gather information on the caging phenomena of the ice lattice on the event. That is; kinetic energy effects, size or mass effects, influence of hydrogen bonding between water molecules and. solute molecules; and steric effects on the magnitude on the recombination yields. These experimental results will greatly assist us in our proposed computer simulation studies (Section 4) of the hot atom recombination events within an-ice-lattice cage.

The first phase of our work and that involving the experimental program is nearly ejghty percent complete. It is too early yet to come to any conclusions or generalizations. However, it would appear that recombination yields are independent of solute concentrations for the frozen aqueous solutions and that the only observed products are the labeled halide and the labejed organic molecule on biomolecule. 
Presented in Table II-III are the percent absolute recombination yields for dilute aqueous solutions of biomolecules in an ice lattice.

Significance. While it may be too early to make statements regarding significance, several facts may emerge. Organic molecules and biomolecules frozen in an ice lattice appear to possess a radioprotection to reactor radiation. There may be a basis for developing new techniques for production of radiopharmaceuticals and for analysis of trace biomolecules in aqueous systems. New insights may be developed regarding caging plenomena. 
TABLE II. PERCENT ABSOLUTE RECOMBINATION YIELDS FOR DILUTE AQUEOUS SOLUTIONS OF BIOMOLECULES IN AN I

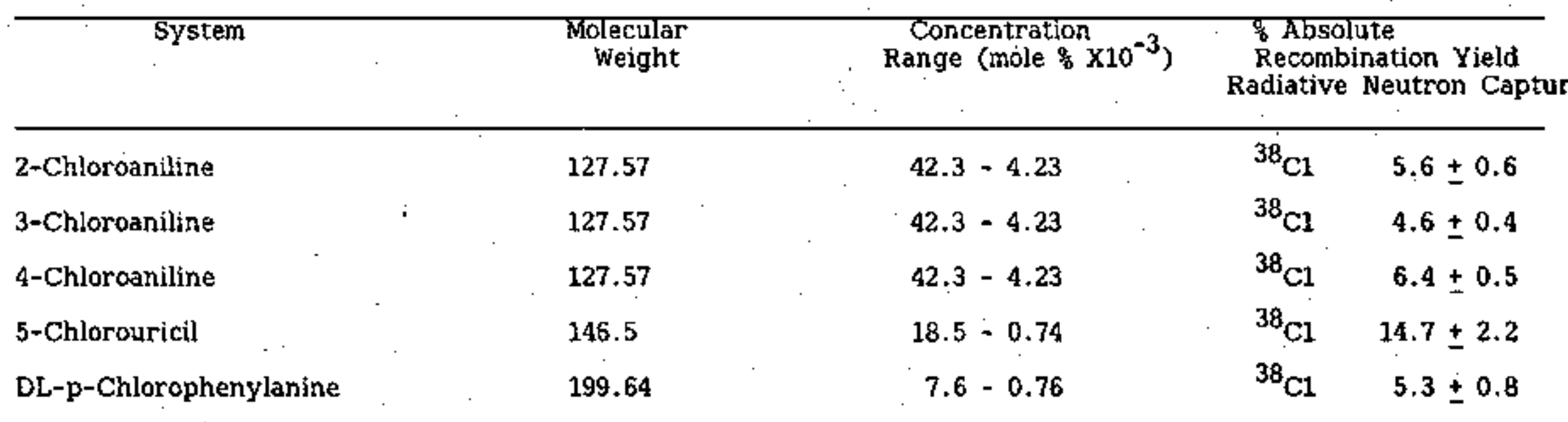


TABLE III. PERCENT ABSOLUTE RECOMBINATION YIELDS FOR DILUTE AQUEOUS SOLUTIONS OF BIOMOLECULES IN AN ICE LATTICE

\begin{tabular}{|c|c|c|c|c|c|c|}
\hline Sỹstem & $\begin{array}{c}\text { Molecular } \\
\text { Weight }\end{array}$ & $\begin{array}{l}\text { Concentration } \\
\text { Range (mole \& } \times 10^{-3} \text { ) }\end{array}$ & Radia & $\begin{array}{l}\text { solute } \\
\text { combination Yield } \\
\text { Neutron Capture }\end{array}$ & Isomeric & Transition \\
\hline 2-Bromoaniline & 172.03 & $15.7 \cdot 1.57$ & ${ }^{80} \mathrm{Br}$ & $16.8 \pm 1.7$ & ${ }^{82} \mathrm{Br}$ & $11.9 \pm 0.1$ \\
\hline 3-Bromoaniline & 172.03 & $14.9 \cdot 1.49$ & ${ }^{80} \mathrm{Br}$ & $8.7 \pm 0.5$ & ${ }^{82} \mathrm{Br}$ & $6.0 \pm 0.9$ \\
\hline 4-Bromoaniline & 172.03 & $15.7-1.57$ & ${ }^{80} \mathrm{Br}$ & $9.5 \pm 0.4$ & ${ }^{82} \mathrm{Br}$ & $7.1 \pm 1.0$ \\
\hline 5-Bromouracil & 190.99 & $18.7-0.187$ & ${ }^{80} \mathrm{Br}$ & $16.0 \pm 2.7$ & ${ }^{82} \mathrm{Br}$ & $14.1 \pm 1.1$ \\
\hline 5-Bromo-2'-Deoxyuridine & 307.4 & $8.8-0.088$ & ${ }^{80} 0_{\mathrm{Br}}$ & $7.2 \pm 0.8$ & $82_{\mathrm{Br}}$ & $5.5 \pm 0.3$ \\
\hline
\end{tabular}


TABLE IV. PERCENT ABSOLUTE RECOMBINATION YIELDS FOR DILUTE AQUEOUS SOLUTIONS OF BIOMOLECULES IN AN

\begin{tabular}{ccc}
\hline System & $\begin{array}{c}\text { Molecular } \\
\text { Weight }\end{array}$ & $\begin{array}{c}\text { Concentration } \\
\text { Range (mole o } \times 10^{-3} \text { ) }\end{array}$ \\
$\begin{array}{c}\text { Recombination Yjeld } \\
\text { Radiative Neutron Capture }\end{array}$ \\
\hline
\end{tabular}

$\begin{array}{lll}\text { 2-Iodoaniline } & 219.03 & 24.6-0.246 \\ \text { 3-Iodoaniline } & 219.03 & 14.2-0.142 \\ \text { 4-Iodoaniline } & 219.03 & 14.0-1.40 \\ \text { 5-Iodouricil } & 237.99 & 14.9-0.015 \\ \text { 3-Iodo-L-Tyrosine (MIT) } & 307.1 & 18.0-0.18 \\ \text { 5-Iodo-2'-Deoxyuridine } & 354.1 & 7.2-0.072 \\ \text { 5-Iodo-5'-Deoxyadenosine } & 377.14 & 7.2-0.072 \\ \text { 3,5-Diido-L-Tyrosine (DIT) } & 434.0 & 8.3-0.083\end{array}$

$\begin{array}{ll}128_{\mathrm{I}} & 32.2 \pm 2.2 \\ 128_{\mathrm{I}} & 29.9 \pm 2.2 \\ 128_{\mathrm{I}} & 28.8 \pm 2.1 \\ 128_{\mathrm{I}} & 29.3 \pm 1.8 \\ 128_{\mathrm{I}} & 16.9 \pm 2.4 \\ 128_{\mathrm{I}} & 22.3 \pm 1.8 \\ 128_{\mathrm{I}} & 13.3 \pm 2.2 \\ 128_{\mathrm{I}} & 20.8 \pm 2.1\end{array}$




\section{Systematics of High Energy Halogen Reactions}

Relevance. Systematic studies of high energy reactions activated by nuclear transformations in gaseous systems are important. From these studies, we can generally ascertain the importance of such parameters as steric, ${ }^{18}$ bond energy, ${ }^{19}$ translational-inertial ${ }^{20}$ and energy degradation factors $^{21}$ on gas-phase hot atom reactions. Moderator studies involving the effect of rare gas additives on the total and individual organic product yields indicate the importance of hot, electronically excited lon, thermal-molecule and thermal-ion reactions. These data characterize the nature of the reactant hot atom and provide data for development of kinetic theories of high energy reactions.

Progress. We are currently studying the systematics of ${ }^{129} \mathrm{I}(\mathrm{n}, \mathrm{\gamma})$

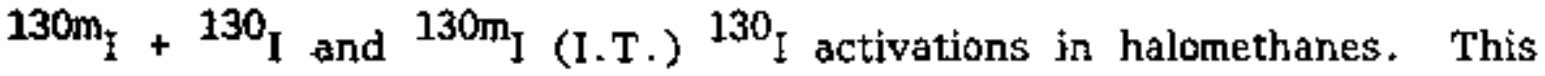
data, in conjunction with that of Nicholas et al. ${ }^{22}$ for. $(n, y)$ - and (1.T.)-activated ${ }^{130_{1}}$ in $\mathrm{CH}_{4}$ and $\mathrm{CD}_{4}$, show trends similar to that reported by Yoong et al. ${ }^{21}$ The organic yield data appear to be linear with respect to the energy degradation factor (EDF) ${ }^{21}$ and independent of bond energy and steric effects. We have found for ${ }^{129_{1}}\left(\mathrm{n}, \gamma_{)}{ }^{130_{I}}+\right.$ 139. $\mathrm{F}$ yields of $4.52^{\circ}, 5.76 \%$ and $8.96 \%$ for $\mathrm{CH}_{3} \mathrm{I}, \mathrm{CH}_{3} \mathrm{Cl}$ and $\mathrm{CH}_{3} \mathrm{E}$. respectively. Yields of $1.75 \%$ for $\mathrm{CH}_{3} \mathrm{I}$ and $4.16 \%$ for $\mathrm{CH}_{3} \mathrm{~F}$ have been found for ${ }^{130} 0_{1}$ (I.T.) ${ }^{130}{ }_{I}$. These data have not been corrected for possible "thermal" hot-atom reaction. Moderator studies currently in progress for these systems will indicate the importance of hot and thermal reactions. 
These studies involving $130 \mathrm{~m}_{\mathrm{I}}+1.30_{\mathrm{I}}$ activated by radiative neutron capture and ${ }^{130} \mathrm{I}$ activated by isomeric transition in gaseous halomethanes. suggest the continuing importance of the energy degradation factor in low-kinetic energy systems.

4. Kinetic Theory Applications of High Energy Reactions and the Mathematical Development of Caging Reactions.

Relevance. A unified kinetic theory of high energy reactions would provide a framework for detailing those characteristics (energetics, kinetics, dynamics and systematics) of reaction found by experimentation and for predicting data trends necessary for application of hot atom systems to high energy chemical technological and environmental problems. A general theory of this kind has yet to be developed. The establishment of a theoretical framework for reactions of heavy monovalent species often possessing positive charge, and easily polarizable, and the characterization of enhancernent reactions would benefit our work and that of others, clarify the current controversy of enhancement reactions and detail specifics in energy, environmental and technological disciplines which at this time cannot be deduced.

Progress. There is no progress to report at the present time. $\mathrm{Mr}$. K. Tomiyoshi is starting to set up his computer simulation studies of hot atom recombination reactions caged by an ice lattice.

5. The Stereochemistry of Energetic Halogen Substitution

Reactions at Asymmetric Carbon Atoms.

Relevance. The fundamental question of whether high-energy halogen atoms replace another halogen by retention or inversion of configuration at asymmetric carbon atoms, $\mathrm{X}_{i}^{*}+\mathrm{RX}_{\mathrm{j}} \mathrm{Xl}$-for $\mathrm{Xj}_{\mathrm{j}} \mathrm{RS}+\mathrm{X} \mathrm{i}$, 
is important to investigate since it. can provide insight into the dynamics of hot-atom reactions. The continuing role of simple physical models for hot atoms with molecules such as the "Impact Model" and the "Inertial Model" can be evaluated and refined.

(a) Evidence for Walden Inversion in High Energy Chlorine-forchlorine substitution Reactions. ${ }^{23}$ This project was a collaborative effort with Dr. A. P. Wolf of Brookhaven National Laboratory. Since this study recently appeared in the Journal of Physical Chemistry, ${ }^{23}$ we will only summarize 'the major results of this study.

Progress. The stereochemistry of high energy chlorine-forchlorine substitution was studied in gaseous and condensed phase 2(S)-chloropropionyl . chloride and 2(R)-chloropropionyl chloride. Greater than $80^{\circ}$ inversion of configuration was observed at the chiral center for both high energy ${ }^{38} \mathrm{Cl}$ and ${ }^{34 m_{\mathrm{Cl}}}$ substitution. Net retention is observed in gaseous $2(5)$-chloro-4-methylvaleryl choloride where steric hindrance to backside attack is enhanced relative to 2(S)-chloropropionyl chloride. Condensed state data suggest caged radical recombination reactions.

Significance- The experimental results of ${ }^{38} \mathrm{Cl}$ and ${ }^{34 \mathrm{~m}} \mathrm{Cl}-$ for-Cl substitution at the asymmetric carbon of $2(\mathrm{~S})-(+)-$ and $2(\mathrm{R})-(-)-$ chloropropionyl chloride in the gaseous and condensed phase indicates a high percent inversion of configuration in the gaseous phase and decrease to a retention to inversion ratio of about one. These results, along with the lack of conformational effects in the condensed phases, give additional support for a cage-radical combination mechanism leading to racenization. The almost identical substitution yields for both ${ }^{38} \mathrm{Cl}$ and ${ }^{38 m} \mathrm{Cl}$ indicate that the initial kinetic energies are not a factor. 
The gaseous phase results indicate that not all hot-atom substitution reactions are fast and direct (as predicted by the impact model) involving a front-side approach but can indeed occur from the backside of the molecule resulting in Walden inversion. From the results of 2(s)-chloro-4-methyl-valeryl chloride experiments, we conclude that the predominant factor controlling the substitution event is steric in character.

\section{Applied Hot Atom Chemistry}

Relevance. While applications of hot atom chemistry techniques or theory may, by themselves, not be energy-related, it is important to realize that the hot-atom chemistry approach may be the most efficient method to assist in a, problem solution. Our main applied interests have been in neutron activation analysis of biological specimens. This collaboration with the Omaha V. A. Medical Center staff has resulted in a waving of the reactor-irradiation fee and, generally, unrestricted use of the reactor and laboratory facility for our high energy chemistry program.

Our entire progress during the current contract period involved (a) the development of a chemical neutron activation analysis procedure and the determination of the vanadium content in shrimp; crab and oysters from four sites off and near Galveston Island, Texas ${ }^{24}$ and (b) preparation of radiopharmaceuticals by Szilard-Chalmers Labeling in an ice lattice.

(a) Determination of Trace-Level Vanadium in Marine Biological Samples by Chemical Neutron Activation Analysis. ${ }^{24}$ Progress. A pre-irradiation chemistry neutron activation analysis procedure employing cation-exchange chromatography was developed for the deter- 
mination of trace-level vanadium in marine biological specimens. The procedure, utilizing a low-power nuclear reactor ( $\left.1 \times 10^{11} \mathrm{n} / \mathrm{cm}^{2}-\mathrm{s}\right)$, consists of wet digestion of the sample, cation-exchange chromatograph employing nitric acid wash to remove the major radioactivatable contaminants (sodium and chloride ions), ammonium hydrozide elution to remove vanadium from the resin, and neutron irradjation and radioassay for ${ }^{52} \mathrm{~V}$. The limit of detection of the method is $30 \mathrm{ppb}$. The determinations of the vanadium content of NBS Standard Reference Material 1571 Orchard Leaves results in a value of $0.60 \pm 0.02 \mathrm{ppm}$. Determinations of the vanadium content in shrimp, crab, and oyster (RSD _ 5\%) from four sites off and near Galveston Island, Texas, showed that the vanadium content is greater in samples taken in the industrialized areas as compared to a non-industrialized section.

Significance. Vanadium can be determined in the parts per billion concentration range in biological specimens. Vanadium content in marine biological specimens is greater in industrialized areas as compared to non-industrialized sites.

(b) Preparation of Radiopharmaceuticals by Szilard-Chalmers Labeling. 25 A new and simple method for the labeling of halogenated organic molecules and biomolecules was developed. Dilute aqueous solutions of the halogenated molecule are irradiated with neutrons in the frozen state. The labeling yields are generally high for the 18 molectles investigated and constant over a large concentration range. The oniy observed labeled organic product is the radiohalogen labeled parent molecule with the halogen at its original site. Unlike neutronirradiated liquid aqueous solutions of the molecules no radiation damage to the molecules is observed for the irradiation times employed. 
Stgnificance. This technique may have importance for the rapid production of radiohalogen labeled high molecular weight or complex organic molecules or biomolecules which cannot be readily labeled by conventional methods. Employing a reactor irradiation, radiation damage to the labeled molecules is minimized. It is realized that a cyclotron has various clear and unique advantages for the production of radiopharmaceuticals, such as the production of positron enitters allowing utilization of positron emission tomography. It will be of interest to test the application of the Szilard-Chalmers labeling procedure in an ice lattice to cyclotron conditions where the radiation flux is more severe than those present in a nuclear reactor. 
Ph.D. Theses Directed:

1. J.A. Merrigan, "Reactions of Bromine Activated by, $(n, \varnothing)$ and (I.T.) Processes Carbon Tetrachloride and the $\mathrm{C}_{6}$-alkanes, 1966.

2. R.M. Lambrecht, "Reactions of Halogen Atoms Activated by Nuclear Processes with Organic Media at $77^{\circ}$ and $298^{\circ} \mathrm{K}, " 1969$.

3. N.J. Parks, "Reactions of Iodine Activated by Radiative Neutron Capture," 1969.

4. E.J. Kemnitz, "Reactions of Selected Halogens and Interhalogens Activated by Radiative Capture and isomeric Transition with : Condensed State Cyclopentane and Aromatic Hydrocarbons," 1970.

5. R.L. Ayres, "Reactions of Iodine Activated by the Neutron Capture Process in Liquid and Solvent Alkanes and Alkenes," 1970.

6. J.B. Nicholas, "Effect of Moderators on the Isomeric Transition Individual Reactions of Iodine-130 and Bromine-82 with Methane and d-Methane," 1971.

7. M.S.C. Yoong, "Kinetic Theory Applications to Halogen Hot Atoms. Activated by Radiative Neutron Capture in Methane, Deutrated Methane, and Polyhalomethanes," 1972.

8. R.W. Helton, "Reactions of Bromine and Chlorine Activated by Radiative Nertron Capture and Isomeric Transition in Gaseous and Condensed Halomethanes," 1972.

9. R.R. Pettijohn, "Radiative Neutron Capture Induced Reactions of Iodine-128 with Gaseous Ethylene and Propylene. Sterochemistry of the $\mathrm{Cl}-\mathrm{Cl}$ Substitution Activated by Nuclear Transformations in Enantiomeric Chlorocarbons," 1973.

10. M.E. Berg, "Theoretical Approaches and Mechanistic Applications in the Gas to Condensed Phase Transition of High Energy Heavy Halogen Reactions in Organic Systems," 1977.

11. Xar-Chun To, "High Energy Reactions of Iodine-128 with Acetylene and Isomers of Butene in the Gaseous, High Pressure and Liquid States." 1978.

12. S.K. Garmestani, "Comparison Between Neutron Activation Analysis and Graphite Furnace Atomic Absorption. Spectrometry for Trace Aluminum Determination in Biological Materials High Energy Reactions of Iodine-128 with Propyne and 1-Butyne in the Gaseous, High Pressure and Liquid States," 1979. 


\section{M.S. Theses Directed}

1. Frank J. Bryant, The Radiolysis of Cyclopentane-Iodine Using Internally Dissolved Iodine-131 and a Nuclear Reactor, 1966.

2. William $\mathrm{K}$. Ellgren, $\mathrm{J} r_{*}$, Radiative Neutron Capture Reactions of Bromine in Liquid Carbon Tetrachloride, 1966.

3. James B. Nicholas, Effect of Moderators on the Isomeric Transition Induced Reaction of Bromine-82 with Methane, 1967.

4. Myung-Hoon Kin, Gas Phase Reactions of Iodine with Pentene Isomers Activated by Radiation and Light, 1974.

5. Alex Loventhal, 1. "A Comparison Between Szilard-Chalmers and a Radiometric Labelling Technique in Kinetic Studies of Photochemical Iodine Addition to Gaseous Pentene Isomers" 2. "Gas to Condensed Phase Transition in Bromine-Ethane Systems. Evidence for Competitive Enhancenent Reactions," August, 1977.

Papers Read By Principal Investigator During Current Contract Period

Plenary Lecture, "Liquid Phase Hot Atom Chemistry: At Crossroads," Leicestershire, United Kingdom, Tenth International Hot Atom Chemistry Symposium, Sept. 5, 1979.

"Product Formation Routes and Chemical Selectivity of High Energy Tenth International Hot Atom Chemistry. Symposium, Sept. 5, 1979.

"Caging Effects of an Ice Lattice on High Energy Chlorine, Bromine and Iodine Geminate Recombination with Biomolecules," Leicestershire, United kingdom, Tenth International Hot Atom Chemistry Symposium, Sept. 5, 1979.

"Preparation of Radiopharmaceuticals by Szilard-Chalmers Labeling and Fladioprotection in an Ice Lattice," San Francisco, California, National Meeting American Nuclear Socjety, Nov. 14, 1979.

PUBLICATIONS OF PRINCIPAL INVESTIGATOR

W.W. Miller, E.P. Rack, E. Burrell, and C.N. Trumbore, Organic Radiation Reactions with Dissolved Radioactive Iodine, J. Chem. Phys., 23, 1457 (1955).

E.P. Rack and A.A. Gordus, Effect of Moderators on the ( $\mathrm{X}$ ) Activated Reactions of the Br-80 with $\mathrm{CH}_{4}, \mathrm{~J}$. Chem. Phys., 23, 1457 (1955).

E.P. Rack and A.A. Gordus, Effect of Inert-Gas Moderators on the $(n, X)$ Activated Reactions of 1128 with $\mathrm{CH}_{4}$, J. Chem. Phys., 34 .
1855 (1961).

E.P. Rack and A.A. Gordus, Reactions of High Energy, Excited I-128 Ions with Gaseous Molecules, J. Chem. Phys., 36, 287 (1962). 
E.P. Rack and A.F. Voigt, Radiation Dose and Iodine Scavenger Effects on Recoil ${ }_{C}$ Reactions in Cyclohexane, $J$. Phys. Chem., 67, 198 (1963).

E.P. Rack and C.E. Lang, and A.F. Voigt, Influence of structure on Gaseous Products from ${ }^{1} \mathrm{C}$ Recoil Reactions In $\mathrm{C}_{6}$ Hydrocarbons, J.

Chem. Phys., 38, 1211 (1963).

J.A. Merrigan and E.P. Rack, Effects of Experimental Parameters on the (n, 8)-Activated Reactions of Bromine with Liquid Cyclohexane, J. Phys.. Chem., 69, 2795 (1965).

J.A. Merrigan, E.P. Rack, Evidence for Bromine-82m Isomeric Transition Activated Reactions in Saturated Hydrocarbon and Alkyl Halides, J. Phys, Chem., 69, 2806 (1965).

I.A. Merrigan, W.K. Ellgren, Jr., and E.P. Rack, Reactions of Bromine Activated by Bromine-82m Isomeric Transition and Radiative Neutron Capture in Liquid and Solid Carbon Tetrachloride and $n$-Hexane, $J$. Chem. Phys, , 44, 174 (1966).

J.A. Merrigan; J.B. Nicholas, R.M. Lambrecht, N.J. Parks, and E.P. Rack, Isomeric Transition Induced Reactions of lodine-130 in Cyclohexane, J. Phys. Chen., 70. 2417 (1966).

J.A. Merrigan, J.B. Nicholas, and E.P. Rack, Nature of $(n, \varnothing)$ and I.T.)-Activated Bromine Reactions in Liquid Jsomers of Hexane, Radiochim. Acta., 6, 94 (1966).

J.A. Merrigan, J.B. Nicholas, and E.P. Rack, A Radiochemical Experiment in Gas-Chromatography, J. Chem. Ed, , 43. 543. (1966):

I.B. Nicholas, J.A. Merrigan, and E.P. Rack, Effect of Moderators on the Isomeric Transition Induced Reaction of Bromine-82 with Methane, J. Chem. Phys. , 46, 1996 (1967).

R.M. Lambrecht and E.P. Rack, Isotope Effects of Iodine Reactions Activated by Radiative Neutron Capture and Isomeric Transition Processes in Liquid Hydrocarbons, J. Chem. Phys., 48,4735 (1968).

y.B. Nicholas and E.P. Rack, Nature of Isomeric-Transition Induced Bromine-82 Reactions with $\mathrm{CH}_{4}$ and $\mathrm{CD}_{4} \mathrm{~J}$. Chem. Phys., $\underline{48}, 4085$ (1958).

N.J. Parks and E.P. Rack, Substituent Effects of Iodine-130 Reactions Activated 26 (1968).

R.M. Lambrecht and E.P. Rack, Complicating Role of Reactions Induced by Isomeric Transitions in Neutron-Activation Analysis for Bromine-82 and Iodine-130, Analyst, 93, 550 (1968). 
R.L. Ayres, E.J. Kemnit2, R.M. Lambrecht, and E.P. Rack, Iodine Organic Yields in Hydrocarbon Matrices as an Indication of Clustering, Complexing, and Fractional Crystalization at $77^{\circ} \mathrm{K}$, Radiochim. Acta 11, 1 (1969).

R.M. Lambrecht, H.K.J. Hahn, and E.P. Rack, Radiative Neutron Capture Organic Yiejds as an Indication of the State of Aggregation of $I C I$ and $I_{2}$ and $C_{6}$-Hydrocarbon Matrices at $77^{\circ} \mathrm{K}$. J. Phys. Chem., 73 , 2779 (1969).

E.J. Kemnitz, H.K.J. Hahn, and E.P. Rack, Isotope and Concentration Effects of Bromine and Polycrystalline Benzene at $77^{\circ} \mathrm{K}$, Radiochim. Acta, 13, $112(1970)$.

H.K.J. Hahn, M. Yoong, and E.P. Rack, Radiometric Analysis of Serum and Tíssue Proteins, J. Lab. and Clin. Medicine, 76, 965 (1970).

R.L. Ayres and E.P, Rack, Szilard-Chalmers Organic Yjelds in Liquid and Solid Alkyl Iodides, Radiochem. Radional. Letters, 3 , (3) 213 (1970).

D.W. Oates, R.L. Ayres, R.W. Helton, K.S. Schwarz, and E.P. Rack, Isomeric Transition Activated Reactions of ${ }^{8} Z_{\mathrm{Br}}$ with Gaseous Methyl Bromide, Radiochem. Radional. Letters, 4(3), 123 (1970).

O.C. Gadeken, R.L. Ayres, and E.P. Rack, Application of Isotopicallylabeled Bromine for the Determination of Trace Unsaturation in Alkanes, Anal. Chem. 42, 1105 (1970).

R.L. Ayres, C.Y. Michejda, and E.P. Rack, Reactions of lodine with Olefins: I. Kinetics and Mechanism of Iodine Addition to Pentene Isomers, J. Amer. Chem. Soc. 93, 1389 (1971).

R.L. Ayres, O.C. Gadeken, and E.P. Rack, Reactions of Iodine with Olefins: If. Radiative Neutron Capture Induces Reactions of I with Various $\mathrm{C}_{5}$ Isomers: Evidence for a Mechanism Other than Autoradiolysis if the Condensed State, J. Phys. Chem., 75,2880 (1971).

R.W. Helton, M. Yoong, and E.P. Rack, Kinetic Energy Isotope Effects of Bromine ${ }_{2}$ Reactions Activated by Radiative Neutron Capture in Gaseous $\mathrm{CH}^{2} \mathrm{~F}$ and $\mathrm{CD}_{3} \mathrm{~F}, J$. Phys. Chem. $\underline{75}, 2072$ (1971).

M. Yoong, $128, C$. Pao, and E.P. Rack, Systematics of (n, Ø)-Activated Hot 128 I Reactions in Gaseous Methane and Halomethanes. The Energy Degradation Factor, J. Phys. Chem., 86, 2685 (1972).

M. Yoong, J.B. Nicholas, and E.P. Rack, Reaction of 130 I Activated by Radiative Neutron Capture and Isomeric Transition in Gaseous $\mathrm{CH}_{4}$ and $\mathrm{DC}_{4}$, and Radiochem. Act., 19, 124 (1973).

R.R. Pettijohn and E.P. Rack, Reactions of Iodine with Olefins. IIt. Radiative Neutron Capture Induced Reactions of Iodine-128 with Gaseous Ethylene and Propylene, J. Phys. Chem., 76, 3342 (1972). 
R.W. Helton, W.M. Grauer, and E.P. Rack, The Gas to Liquid to Solid Transitions in Halogen Hot Atom Chemistry. 1. Reactions of (n. J)-Activated Bromine-80 in Methyl Fluroide, J. Chem. Phys., 19, $44(1973)$.

A.J. Blotcky, L.J, Arsenault, and E.P: Rack, An Optimum Procedure for Determination of Selenium-77m by Neutron Activation Anajysis in Biological Specimens, Anal. Chem., 45, 1056 (1973).

R.W. Helton, D.W. Oates, and E.P. Rack, Reactions of ${ }^{82}$ Br Activated by Isomeric Transition in $\mathrm{CH}_{4}$ : A re-evaluation, Bull. Chem. Soc.; Japan, 46, 2877 (1973).

W.M. Grauer, E.P. Rack, and R.M. Lambrecht, Radiative Neutron Capture and Isomeric Transition Isotope Effects in Bromine Reactions with Liquid Cyclohexane and Carbon Tetrachloride. A Re-evaluation, Radiochem. Radional. Letters, 16, 301 (1974).

A.J. Blotcky, D.M. Duven, W.M. Grauer, and E.P. Rack, Determination of

Iodine and Urine by Neutron Activation Analysis. Application of the Szilard-Chalmers Effect, Anal. Chem. . 46, 838 (1974).

W.M. Grauer, M. Berg, R.W. Helton, and E.P. Rack, The Gas to Liquid to

Solid Transitions in Halogen Hot Atom Chemistry. II. The System1327 atics of Bromine Reacting with Halomethanes, J. Phys. Chem., 79, (1975).

A.J. Blotcky, D. Hobson, E.P. Rack, A Comparison of Destructive and Nondestructive Neutron Activation Analysis Methods for the Determination of Trace Iodine in Saliva, Radiochem. Radioanal. Letters, 24, 291 (1976).

K.C. To, M.E. Berg, W.M. Grauer, and E.P. Rack, Gas to Liquid to Solid Transition in Halogen Hot Atom Chemistry. III. Evidence for an Excited Reaction Intermediate in the (n,X)-Activated Reactions of Iodine with Acetylene, J. Phys. Chem. 80, 1411 (1976).

A.J. Blotcky, D. Hobson, J.A. Leffler, E.P. Rack and R.R. Reckler, Determinations of Trace Aluminum by Neutron Activation Analysis, Anal. Chem. 48,1084 (1976).

A. Loventhal, M. Kim, and E.P. Rack, A Comparison between a Szilard-Chalmers and a Radiometric Labeling Technique in Kinetic Studies of Photochemical Iodine Addition to Gaseous Pentene Isomers, Radiochern. Radioanal. Letters 26, 239 (1976).

M. Albanese, D.W. Brooks, V.W, Day and E.P. Rack, Piagetian Criteria as Predictors of Success in First Year Chenistry Courses, J. Chem. Ed. 53, 571 (1976). 
A.J. Blotcky, D. Hobson and E.P. Rack, A Comparison of Destructive and Non-destructive Neutron Activation Analysis Methods for the Determination of Trace Iodine in Saliva, Radiochem. Radioanal. Letters $\underline{24}, 291$ (1976).

M.E. Berg, A. Loventhal, D.J. Ade!man, W.M. Grauer, and E.P. Rack, Gas to Liquid to Solid Transition in Halogen Hot Atom Chemistry. 4. The Suggestion of Multiple Enhancement Reactions in High Energy Iodine-128-Ethane Systems, J. Phys. Chem. 80, 837 (1977).

K.C. To, M.E. Berg and E.P. Rack, Reactions of Iodine with Olefins. 4. Preferential Site Attack of Electrophilic High Energy Iodine in Gaseous, High Pressure and Liquid Butene-1 $\mathcal{J}$. Phys, Chem., 81, $1239(1977)$.

R.R. Recker, A.J. Blotcky, J.A. Leffler, and E.P. Rack, Evidence for Aluminum Absorption from the Gastrointestinal Tract and Bone Deposition by Aluminum Carbonate Ingestion with Normal Renal Function, J. Lab. Clin. Med, , 90, 810 (1977).

M. E. Berg, K. C. To and E. P. Rack, A Computer Simulation Model for Evaluating Simple Kinetic Theory Parameters in Hot Atom Chemistry, Radiochem. Acta 24, 37 (1977).

A. Loventhal, M. E. Berg and E. P. Rack, Effects of a Collapsing Molecular Environment on High Energy Bromine Reactions in Ethane, Radiochem. Acta 24, 91 (1977).

K. Garmestani, A. J. Blotcky, and E. P. Rack, Comparison between Neutron Activation Analysis and Graphite Furnace Atomic Absorption Spectrometry for Trace Aluminum Determination in Biological Materials, Anal. Chem. 50, 144 (1978).

A. J. Blotcky, E. P. Rack, R. R. Recker, J, A. Leffler and S. Teitelbaum, Trace Aluminum Determination and Simpling Problems of Archeological Bone Employing Destructive Neutron Activation Analysis, J. Radioanal. Chem. (U.S.A. National issue) $\underline{43}, 379$ (1978).

K.-C. To, M. E, Berg and E. P. Rack, 5. The Systematics of Electrophilic High Energy Iodine in Gaseous, High Pressure and Liquid Isomers of Butene, J. Phys. Chem., 82, 761 (1978).

T. R. Accinani, Y. Su, H. J. Ache and E. P. Rack, Effects of Solvent-Solute Interactions on the Stereochemical Course in High Energy Chlorine-38 for Chlorine Substitution in meso- and rac 1,2-Dichloro-1,2-difluoroethane in Solution, J. Phys. Chem. $\underline{82}$, 975 (1978).

A. J. Blotcky, C. Falcone, V. A. Medina and E. P. Rack, Determination of Trace-Level Vanadium in Marine Biological Samples by Chemical Neutron Activation Analysis, Anal. Chem., 51, 178 (1979). 
L. I. Arsenault, A, J. Blotcky, V. A. Medina and E. P. Rack, Caging Effects of an Ice Lattice on High Energy lodine Geminate Recombination with Biomolecules, J. Phys. Chem, , 83, 893 (1979).

A. P. Wolf, P. Schueler, R. R. Pettijohn, K.-C. To and E. P. Rack, Evidence for Walden Inversion in High Energy Chlorine-forChlorine Substitution Reactions, J. Phys. Chem., 83, (1979).

S. K. Garmestani and E. P. Rack, Gas to Liquid to Solid Transition in Halogen Hot Atom Chemistry-5. Preferential site Attack with Formation of an Exicted Reaction Intermediate by High-Energy Iodine with Propyrl, J. Phys. Chem. 83, 2317 (1979).

S. K. Garmestani, M. L. Firouzbakht and E. P. Rack, Ges to Liquid to Solid Transition in Halogen Hot Atom Chemistry. 6. Product Formation Routes and Chemical Selectivity of High Energy Iodine Reactions with Butyne Isomers, J. Phys. Chem. 83, 2827 (1979).

\section{In Press on Submitted Manuscripts}

E. P. Rack, Liquid Phase Hot Atom Chemistry: At Crossroads, Radiochem Acta, 26, 000 (1979).

E. P. Rack, Tenth International Hot Atom Chemistry Symposium, Radiochen. Acta, 26, 000 (1979).

L. I. Arsenault, A. J. Blotcky, M. L. Firouzbakht, and E. P. Rack, Preparation of Radiopharmaceuticals by Szilard-Chalmers Labeliing. and Radioprotection in an Ice Lattice, J. Radio Anal. Chem. Suto modion in press 


\section{PERSONNEL}

1. Project Director
E. P. Rack

2. Post Doctoral Associates

Kar-Chun To (at Brookhaven National Laboratory)

K. Garmestani (Teaching Post Doctoral Associate)

3. Graduate students

K. Garmestani (PhD. 1979)

F. El Amri

M. L. Firouzbakht

K. Tomiyoshi

4. Undergraduate Students

V. A. Medina (terminated 1979)

J. Sorrell (terminated 1979)

A. Scott (terminated 1979)

5. Omaha Medical Center Collaborators

L. J. Arsenault

A. J. Blotcky 


\section{REFERENCES}

1. K. -C. To, M. E. Berg, W. M. Grauer and E. P. Rack, J. Phys, Chem. , 80, 1411 (1976).

2. S. K. Garmestani and E. P, Rack., J. Phys. Chem., 83, 2316 (1979).

3. S. K. Garmestani, M. C. Firouzbakht and E. P. Rack, I. Phys. Chem. 83, 2827 (1979).

4. R. L. Ayres, O. C. Gadeken and E. P. Rack, J. Phys. Chem. $1971,75,2880$.

5. R. L. Ayres, C. J. Michejda and E. P. Rack, J. Phys. Chem. Soc. $1971,93,1389$.

6. A. Loventhal, M. Kim and E. P. Rack, Radiochem. Radioanal. Lett. 1976, 239.

7. R. R. Pettijohn and E. P. Rack, J. Phys. Chem. 1972, 76, 3342.

B. K.-C. To, M. E. Berg and E. P. Rack, I. Phys. Chem. 1977, 81, 1239 .

9. K.-C. To, M. E. Berg and E. P. Rack, I. Phys. Chem, 1978, 82, 761.

10. D. D. Wilkey, J. F. Brensike and J. E. Willard, J. Phys. Chem., 71. 3580 (1967).

11. L. I. Arsenault, A. J. Blotcky, V. A. Medina and E. P. Rack, I. Phys. Chem. 83, 893 (1979).

12. K. M. Bansal, L. K. Patterson, and R. H. Schuler, J. Phys. Chem. , 2386 (1972).

13. L. K. Patterson, K. M. Bansal, J. Phys. Chem. 762392 (1972).

14. P. Neta, I. Phys, Chem. 762399 (1972).

15. K. Bhatia, R. H. Schuler, J. Phys. Chem. 77 1888 (1973).

16. K. Bhatia, R. H. Schuler, I. Phys, Chem. 771356 (1973).

17. L. Kevan, J. Phys. Chem. 763830 (1972).

18. I. Spicer and R. Wolfgang, I. Amer. Chem. Soc., 90, 2426 (1968).

19. T. Smail, R. S. Igen and F. S. Rowland, I. Phys. Chem. $\underline{75}$. 1324 (1971). 
20. N. Colebourne, J. F. J. Todd, and R. Wolfgang, I, Phys. Chem. $\underline{71}, 2875(1967)$.

21. M. Yoong, Y. C. Pao and E. P. Rack, J. Phys. Chem., 76, 2685 (1972).

22. J. B. Nicholas, M. Yoong, and E. P. Rack, Radiochem. Acta, 19, 124 (1973).

23. A. P. Wolf, P. Schuster, R. R. Pettijohn, K.-C. To and E. P. Rack, I. Phys. Chem. . 83, 1237 (1979).

24. A. J. Blotcky, C. Falcone, V. A. Medina, and E. P. Rack, Anal. Chem., $\underline{51}, 178$ (1979).

25. I. J. Arsenault, A. J. Blotcky, M. L. Firouzabacht and E. P. Rack, I. Radioanal. Chem, submitted for publication. 